NBER WORKING PAPER SERIES

\title{
POLICIES TO ENCOURAGE INFLOWS \\ OF TECHNOLOGY THROUGH \\ FOREIGN MULTINATIONALS
}

\author{
Magnus Blomström
}

Ari Kokko

Working Paper No. 4289
NATIONAL BUREAU OF ECONOMIC RESEARCH 1050 Massachusetts Avenue
Cambridge, MA 02138
March 1993

This paper is part of NBER's research program in International Trade and Investment. Any opinions expressed are those of the authors and not those of the National Bureau of Economic Research. 
NBER Working Paper \#4289

March 1993

\title{
POLICIES TO ENCOURAGE INFLOWS \\ OF TECHNOLOGY THROUGH \\ FOREIGN MULTINATIONALS
}

\begin{abstract}
Do host countries aiming to maximize the inflows of technology through foreign multinationals have any policy alternatives to formal technology transfer requirements and performance requirements? To answer this question, the present paper examines some possible determinants of the technology imports of U.S. majority-owned foreign affiliates in 33 host countries. The results show that the affiliates' technology imports increase with the host countries' domestic investment levels and education levels, but that various performance requirements are negatively related to technology transfer. This suggests that policies promoting local investment, competition, and education may sometimes be alternatives to direct controls and requirements.
\end{abstract}

Magnus Blomström

Stockholm School of Economics

P.O. Box 6501

11383 Stockholm

SWEDEN

and NBER
Ari Kokko

Stockholm School of Economics

P.O. Box 6501

11383 Stockholm

SWEDEN 
Policies to Encourage Inflows of Technology through Foreign Multinationals ${ }^{1}$ Magnus Blomström and Ari Kokko

\section{Introduction}

The debate on the role of government policies for economic performance has, in recent years, turned from discussing the choice between free markets and government intervention to asking what types of intervention are good and bad.

One reason is that almost all governments, irrespective of their political orientation, have chosen to play an active role in their economy (see e.g. Bardhan, 1990). However, the definition of successful intervention is still disputed, although an important lesson from the recent experience of several Asian economies seems to be that governments should make use of market forces in their efforts to influence the direction and character of economic growth: markets and competition need to be retained to discourage wasteful use of resources and to encourage learning and technical advances.

The distinction between good and bad intervention has been noted also

\footnotetext{
${ }^{1}$ The research reported here is part of the NBER program in International Studies, and has been supported by the Swedish Council for Research in the Humanities and Social Sciences and the Swedish Agency for Research Cooperation with Developing Countries. Helpful comments from Robert Lipsey on an earlier draft of this paper are gratefully acknowledged. Any opinions are those of the authors, and do not necessarily represent the views of the National Bureau or the sponsoring agencies.
} 
in the trade policy debate. For instance, Bhagwati (1988) argues that policies based on prescriptions rather than proscriptions generally produce better economic performance. One reason is that the latter types of intervention tend to stifle initiative and hurt entrepreneurship and growth, whereas the former leave large areas untouched and also allow people to do what is not formally prescribed. Another reason is that proscriptions tend to divert resources into unproductive efforts to evade the rules.

A similar discussion is now emerging in the literature on foreign direct investment (FDI) and technology transfer. Some of the main host country benefits of FDI are considered to stem from the inflows of new technology to affiliates of multinational firms (MNCs), since these flows create a potential for technology spillovers to the host country's local firms (Blomström, 1989; Kokko, forthcoming). What policy measures should host countries adopt to get the MNCs to transfer more technology, and to increase the potential for spillovers? The traditional view has been that different types of regulations are necessary. Many governments have therefore started to frame the environment within which multinationals operate by introducing various performance requirements for their behavior. Special attention has been given to policies regarding technology transfer, and a number of measures intended to encourage or force multinational firms to increase their technology transfer have been introduced over the years, including requirements for local content and local R\&D. 
A different view on how to influence the multinationals' technology transfer has recently been suggested by Wang and Blomström (1992). They develop a model where the MNC affiliate's decision to import technology is explicitly related to profit maximization, i.e. the affiliate imports technology until the marginal revenue of further import is equal to the marginal cost. Technology imports raise revenue (although at a diminishing rate) because the demand for MNC products is positively related to the technological gap between the affiliate and competing host country firms. However, there are also costs involved in each transfer operation (e.g. for training of local workers), and more modern technologies are increasingly more expensive to transfer.

The model's implications for host country policies match those from the recent debate on government intervention in the trade literature. One result is that requirements which increase the affiliates' technology transfer costs may have perverse effects, i.e. reduce technology imports, unless there are strong sanctions for those who do not abide by the rules. Another conclusion, pointed out by Wang and Blomström (1992), is that host country governments might increase the transfer of technology through foreign affiliates by making sure that they are exposed to local competition and by supporting domestic firms in their efforts to learn from the foreigners. Increased competitiveness in local firms means that the technology gap becomes narrower, which reduces the demand for the affiliates' products and gives them a reason to bring in new 
technology in order to restore their advantages. Analogously, government intervention that reduces the affiliates' transfer costs, e.g. education policies that raise the host countries' learning capabilities and improve local labor skills, may encourage higher technology imports. In other words, policies making use of market forces may be preferable to intervention in the form of conventional technology transfer and performance requirements.

To the best of our knowledge, there is no host government that has methodically tried to encourage foreign affiliates to import technology by using competition and education policies instead of formal requirements, so it is not possible to compare the effects of the various types of policy intervention. However, there is a large variation in requirements, competition, education, and other characteristics across host countries, and it should be possible to observe systematic cross-country differences in the affiliates' technology imports if these characteristics influence the marginal costs and benefits of technology transfer, as hypothesized in the Wang-Blomström model. In this paper, we will therefore examine how the technology imports of U.S. majority-owned foreign affiliates in 33 host countries are related to proxies for the host countries' requirements, levels of local competition, and learning capabilities. The results are intended to provide some insights about how host countries can persuade foreign-owned multinationals to bring more technology to their affiliates.

The paper is organized as follows. Section 2 presents data, variables, 
and statistical hypotheses. Section 3 reports the statistical results and Section 4 summarizes and concludes the paper.

\section{Data, Variables, and Statistical Hypotheses}

\section{A. Dependent Variables: Measures of Parent-Affiliate Technology Transfers}

The transfer of the parent MNC's proprietary technology can take different forms, including technical documentation, education and training of the affiliate's labor force, exchanges of technical personnel, shipments of machinery and equipment, and continuing communication to solve whatever problems occur in the production processes. Each transfer is likely to include several of these modes; yet, only a few of the transfer forms are usually recorded. Moreover, there are reasons to be cautious even when data are available. One problem is that all parent companies have not developed precise methods for pricing the technology that is supplied to affiliates. Another complication has to do with transfer pricing: intra-corporate technology payments are likely instruments for concealing repatriated profits and evading host country taxes, because market prices for the technologies are usually lacking (see e.g. Caves, 1982).

The data on technology transfers used in this study are from the U.S. Department of Commerce surveys of U.S. Direct Investment Abroad, and refer to the manufacturing operations of majority-owned foreign affiliates (MOFAs) of U.S. multinationals in 33 host countries in 1982 (U.S. Department of 
Commerce, 1985). ${ }^{1}$ We will define several alternative proxies for the affiliates technology imports, based on data for the U.S. MOFAs total payments for royalties and license fees, and their imports of capital equipment from the United States. In addition to the possible data problems mentioned above, two additional sources of errors should be noted. The data on the affiliates' royalties and license payments include payments to non-affiliated persons (although intra-MNCs transactions make up 93 per cent of the total payments), and imports from all U.S. sources are included in the data on capital equipment. The proxies therefore refer to the affiliates' technology imports from all sources rather than to transfers between parents and affiliates.

The total value of the payments for royalties and licenses in 1982 by U.S. MOFAs in the manufacturing sector amounted to 3,051 million U.S. dollars. Out of this, 2,856 million dollars were accounted for by affiliates in developed countries, and only 195 million by affiliates in developing countries. In the same year, 1,358 million dollars worth of capital equipment was exported from the U.S. to the affiliates, with 874 million going to developed country affiliates and 484 million to the developing countries. Table 1 presents some measures of the royalty and license payments (LICENSE) and imports of capital equipment (CAPIMP) by U.S. MOFAs operating in different industry groups in 1982 . 


\section{Insert Table 1}

It can be seen that the differences between industries are very large for the LICENSE variables: the payments range from 90 dollars per employee (or a tenth of a per cent of the value of sales) in transport equipment to 2,890 dollars per employee (or over three per cent of sales) in machinery. The variation in equipment imports is smaller, but still notable.

The cross-country data that we will use for the regression analysis are only available for total manufacturing, because numerous industry level observations have been suppressed at the source for reasons of confidentiality. However, the large inter-industry differences illustrated by Table 1 suggest that the industry distribution of affiliates may show through in the figures for total manufacturing. For example, in Sweden, most U.S. investment is in machinery, which clearly is the most "licensing-intensive" industry group, and technology payments can be expected to be high for this reason alone. It is even possible that the industry effects dominate other explanations for cross-country differences in technology imports. To come around this problem, we have therefore constructed some alternatives to the simple LICENSE measure.

The first of these, termed LICDIF, attempts to measure the difference 
between actual license payments and what we might "expect" on the basis of the industry distribution of U.S. MOFAs in each host country. The measure is constructed using data on average license payments per employee (weighted by employment shares, from Table 1) and employment data for U.S. affiliates (from U.S. Department of Commerce, 1985). ${ }^{2}$ To get a measure of expected license payments for each country/industry group, we multiplied the affiliates' employment in each industry in each country by the average license payment for that industry. An estimate of the total expected license payment for each host country, taking into account its industry distribution of affiliates, was then obtained by summing across industries for each country. To get the variable LICDIF, finally, we subtracted these estimates from the actual license payments of the host country. Contrary to the ratio of actual license payments to labor, LICDIF is not automatically high if a large share of the country's affiliates are in "licensing-intensive" industries, since the expected license payment in that case is also high. Instead, LICDIF is hypothesized to be high only when the affiliates import more technology than what is "normal". Measures for CAPDIF, the difference between actual and expected imports of capital equipment, were calculated analogously.

The differences between developed and developing countries, in particular for payments of royalties and license fees, are also strikingly large, as noted above. Differences in industry distribution explain part of this, but there may be other factors that depress the technology flows to developing 
countries. These include the weaker learning capability of developing countries, weak infrastructure, fragmented markets, political instability, and a host of other matters that we have no comprehensive data for. For some of the tests, we have therefore recalculated the dependent variables with separate expectations for developed and developing countries - in other words, the measures for expected license payments from developing countries have been based on average license payments from developing countries only. The resulting variables, which are corrected both for the industry distribution and development level, are termed LICDIF* and CAPDIF*, and allow us to concentrate more directly on the effects of the host country characteristics we have data for. All of the measures have been scaled in two ways, i.e. divided by the affiliates' sales and by their employment, to provide several alternative proxies for technological effort. The six versions of the dependent variable are summarized in Appendix Table $1 .^{3}$

B. Explanatory Variables: Requirements, Local Competition, and Learning Capability.

Levels of economic development, political stability, technology transfer requirements, local competition, learning capability, and a host of other characteristics are likely to vary across host countries. We hypothesized in the introduction that it should be possible to observe systematic cross-country differences in the MNC affiliates' technology imports if these host country 
characteristics influence the marginal costs and benefits of technology transfer, as argued by Wang and Blomström (1992). Since most of these features are difficult to measure empirically, we have restricted our analysis to proxies for three variables - technology transfer and performance requirements, local competition, and local learning capability - but even these suffer from some obvious weaknesses. ${ }^{4}$

First, to measure the host countries' technology transfer and performance requirements, we have calculated two proxies from U.S. Department of Commerce (1985), Table II.I.3. The first of these, labelled TREQS, focuses directly on technology transfer requirements, and measures the share of U.S. affiliates in each host country in 1982 that were reported to operate under requirements to use the most advanced technology available, perform R\&D locally, have access to the U.S. parent's patents, or transfer skills to local personnel. We hypothesize that these requirements increase the affiliates' technology transfer costs, and we therefore expect TREQS to have a negative impact on the affiliates' imports of technology. However, the impact may not be very significant, for two reasons. Although the requirements captured by TREQS are likely to increase transfer costs, it is possible that there are some cases where they are backed up by strong sanctions, so that only the firms that actually transfer much technology are allowed to stay in operation. Secondly, the effects of the requirements on both transfer costs and actual transfers may sometimes be insignificant, because many of the rules are 
ambiguous: the affiliate decides which technologies are viable, there may not be any direct connection between $R \& D$ and imports of new technology, and access to the parent's patents does not ensure actual transfer of technology.

The alternative proxy PREQS reflects the share of affiliates that faced various quantitative performance requirements in 1982 (including import restrictions, minimum local content, and minimum local employment requirements). This may be more suitable for present purposes, because quantitative rules are less ambiguous and easier to uphold, and because the performance requirements that increase the extent of local participation also increase the costs of transferring and using advanced technologies. Hence, we hypothesize that PREQS will have a negative impact on technology transfer.

Both TREQS and PREQS cover all non-bank affiliates of U.S. parents with more than 10 per cent U.S. ownership, rather than only the majority-owned affiliates included in the measures of technology imports. The general pattern, with OECD countries and some South-East Asian economies registering the lowest formal requirements and Latin American and South Asian nations exhibiting the highest ones, is the one we would expect also for more comprehensive measures of technology transfer requirements. ${ }^{5}$

We have proxied local competition with two alternative measures of investment intensity in the host economy. The assumption is that investment reflects either new entrants into industry, or an upgrading of the technological level of existing firms, both of which increase competition and reduce the 
technology gap between the affiliate and local firms. The variables are INV/OUTPUT (the gross fixed capital formation/gross output ratio) and INV/EMPL (gross fixed capital formation per employee) and both cover the host countries' entire manufacturing sectors, excluding the U.S. affiliates. They are based on data from various issues of the United Nations' Industrial Statistics Yearbook, and for the INV/EMPL variable, capital formation figures have been converted from local currency to U.S. dollars and corrected for international differences in capital goods prices using data from Summers and Heston (1988). Investment by multinationals from other countries than the United States has not been subtracted, which means that "local competitors" are defined as all non-U.S. actors in the host country market, including MNC affiliates from other countries. ${ }^{6}$ INV/OUTPUT and INV/EMPL are used interchangeably in the estimations: the variables provide alternative, although related, measures of competition, as seen by the simple correlation of about 0.5 (see Appendix Table 2). The hypothesis from the theoretical model is that local competition reduces the technology gap and the demand for the affiliates' products, and increases the marginal revenue of further technology transfer. Hence, we expect the affiliates' technology imports to be positively related to our proxies for local competition.

To account for the cross-country differences in learning capabilities and labor skills, we use the variables ED2ND and ED3RD. They measure the share of the appropriate age-group in secondary and third level education in 
each host country 1980, and are taken from UNESCO's Statistical Yearbook 1990, Table $3.2 .{ }^{7}$ We expect both variables to have a positive influence on the affiliates' technology imports, because the marginal technology transfer costs are lower when the level of education is higher. However, it should be noted already here that the small variance in ED2ND is likely to reduce its observed significance.

\section{Statistical Results}

\section{A. Payments for Royalties and License Fees by MNC Affiliates}

The results of OLS estimations of the U.S. MOFAs' license payments are reported in Table 2. The dependent variables in equations (1) and (2) are based on the observed license payments (LICENSE), equations (3) and (4) refer to variables that are adjusted for the industry distribution of affiliates (LICDIF), and those in equations (5) and (6) have been adjusted also for the host countries' development levels (LICDIF*).

\section{Insert Table 2 here}

Looking first at the estimations with LICENSE, we find that our proxies for local competition and education are positively related to the affiliates' 
license payments, whereas the effect of requirements seems to be negative. The coefficients for the two variants of the local competition proxy, INV/EMPL and INV/OUTPUT, are both highly significant, but the former performs better in terms of $\overline{\mathrm{R}}^{2}$. This holds for the other equations as well, and the reason is probably that INV/EMPL captures some of the differences between the countries' capital intensities: high rates of gross investment per employee are likely to be connected to high capital-labor ratios (simply because much capital must be replaced in every period), and also to high levels of technical skills that facilitate the affiliates' technology imports.

The coefficients for the requirement proxies TREQS and PREQS are both negative, but TREQS is seldom significantly different from zero, and it is therefore not shown in the table. This may suggest that the requirements captured by TREQS may sometimes include rules that force the affiliates to import technology irrespective of the costs, or that TREQS has little effect on the affiliates' costs of importing technology, as discussed earlier. Both ED2ND and ED3RD have the expected positive coefficients, but they are not highly significant.

However, it is difficult to draw firm conclusions from the results for LICENSE, although they seem to confirm some of our hypotheses. As discussed earlier, the cross-country differences in licensing intensity may be caused mainly by differences in the industry distribution of affiliates, and not by our explanatory variables. The observed effects of competition, education, 
and requirements may therefore be related to decisions about industry localization rather than to the determinants of the affiliates' technology imports.

In equations (3) and (4), an attempt has been made to account for the cross-country differences in the industry distribution of affiliates. The explanatory power of the equations improves somewhat, and the coefficient for ED3RD becomes significant. However, INV/OUTPUT loses its significance. A possible reason for this is that the license payments from developed and developing countries differ so much that local competition alone, as proxied by INV/OUTPUT, cannot explain the pattern. INV/EMPL contains some information about capital-intensities, and may be more significant for that reason.

The major result of the crude adjustment for development levels in the variable LICDIF* is that INV/OUTPUT becomes more efficient, whereas the estimated coefficients of PREQS and ED3RD become less significant, although their signs remain as expected. In equation (5), the coefficient of INV/EMPL is significant at the one per cent level, whereas those for PREQS and ED3RD are not significantly different from zero. In equation (6), the coefficient of the alternative competition proxy INV/OUTPUT is significant at the five per cent level, but the confidence levels for requirements and education are below 10 per cent. The reason why the proxies for education and requirements are not significant in these two equations is probably that their effects have already 
been captured by the adjustment for development levels in the dependent variable.

Summing up these results, there is fair support for the hypotheses that the affiliates' technology payments are positively related to the host countries' domestic investment levels and education levels, but negatively related to various performance requirements.

\section{B. Imports of Capital Equipment by MNC Affiliates}

Before discussing the determinants of the affiliates' capital imports, it is necessary to make some comments on the relation between imports of capital equipment and technology transfer in general. The reason is that there may be some substitution between different modes of technology transfer. For instance, we hypothesize that higher learning capability and labor quality in the host country are accompanied by larger transfers of technology to affiliates, but the technology flows may not take the form of capital goods imports. In countries with high levels of education, it may be possible to find local suppliers of advanced machinery and equipment - the needed machine technology can probably be imported in the form of blueprints - and CAPIMP may remain low although technology transfers in general are large. In the less developed countries, on the other hand, levels of education are low, but CAPIMP may be relatively high anyway because all advanced machinery may have to be imported. Similarly, shortages of skilled labor might lead 
developing country affiliates to choose technologies that are embodied in capital goods, rather than "soft" technologies that require skilled labor. This suggests a more complex case, with several effects pulling in different directions. The estimations may therefore be seen as tests of which of these effects are the strongest.

There are question marks also concerning the effects of requirements. Most technology transfer requirements usually aim to control the transfer of disembodied technology, e.g. by demanding special training of the local labor force, whereas performance requirements are often initiated to reach some target level of local content or to restrict imports of intermediary goods for macro-economic reasons. It is not certain that these rules have major effects on imports of machinery and equipment. In fact, if requirements are strong (and increase the cost to transfer soft technologies) they might even lead affiliates to prefer to transfer embodied technology, because it is less likely to spill over to local competitors.

Table 3 presents some of the estimations for imports of capital equipment by U.S. MOFAs. The dependent variable in equations (7) and (8) is based on the directly observable data for the affiliates' imports of capital equipment (CAPIMP), but has been adjusted for the industry mix of the affiliates operating in the host country in equation (9) (CAPDIF), and also for the host country's development level in equation (10) (CAPDIF*). The results are weaker than those for the license measures - most notably, $\bar{R}^{2}$ is 
significantly lower - but the positive coefficient of local investment remains significant at the 10 per cent level for all variants of the equation. The coefficient of PREQS is also positive in all estimations, although never significant. The signs of the coefficients of TREQS and the education proxies vary, but none of them is significantly different from zero.

\section{Insert Table 3}

Thus, there is some evidence that investment by local competitors may force the affiliates to higher imports of technology that is embodied in capital goods. The costs posed by the host countries' performance and technology transfer requirements do not seem to discourage imports of capital equipment - if anything, there is a slight positive effect of requirements, that perhaps reflects the preference to import more embodied technology when the costs for other transfer modes are high - and differences in the level of education do not have any determinate effect. However, the weak fit of the model suggests that there are other important determinants of capital equipment imports than those included in the model.

We also tested the hypotheses for a dependent variable constructed as the sum of CAPIMP and LICENSE, to examine how the differences in the 
"aggregate" technology imports of U.S. affiliates can be explained. The estimated equation (for the 31 countries where data were available), with the dependent variable $\mathrm{Y}$ defined as the ratio (CAPIMP + LICENSE) / LABOR, and with t-statistics in parentheses, is

$$
\begin{gathered}
\mathrm{Y}=-0.07+1.00 \mathrm{INV} / \mathrm{EMPL}-0.32 \text { PREQS }+0.38 \text { ED3RD } \\
(0.18) \quad(4.72)^{* * *}
\end{gathered}
$$

It can be seen that the impact of local competition (as measured by INV/EMPL) appears to be even more significant here than in any of the other estimations. The negative coefficient of PREQS is also significant, but that of ED3RD is not, although it has the expected positive sign. Moreover, there are notable improvements in the overall fit of the equation: $\bar{R}^{2}$ increases to 0.55 , and the F-value to 13.47.

\section{Concluding Remarks}

The purpose of this paper has been to determine whether host countries aiming to maximize the inflows of technology through foreign multinationals have viable policy alternatives to formal technology transfer requirements. On the basis of a simple theoretical model of technology transfer, proposed by Wang and Blomström (1992), we hypothesized that policies making use of market forces may be more effective than conventional technology transfer 
requirements. For instance, policies increasing the level of competition in the host country may erode the MNC affiliate's technological advantages, and force it to import new technology from its parent. Similarly, policies improving local learning capability and labor skills may reduce technology transfer costs, and encourage imports of technology.

To test these hypotheses, we examined how cross-country differences in the technology imports of U.S. affiliates in 33 host countries (calculated from data on the affiliates' payments for royalties and license fees and their imports of capital equipment from the U.S. in 1982) were related to proxies for technology transfer requirements, local competition, and labor skills in the host countries. The results consistently showed that the technology imports of MNC affiliates increased with our proxies for the competitive pressure in the host economy. The technology transfers that were reflected by data on payments of royalties and license fees were negatively related to performance requirements, but the requirements did not have any clear effect on imports of technologies embodied in machinery and equipment. Moreover, the host countries' levels of education had a positive impact on the affiliates' payments of royalties and license fees, but no significant effect on the affiliates' imports of capital equipment.

One policy conclusion of these findings is that host country governments may choose to support local investment, competition, and education rather than to rely on controls and direct supervision of FDI to secure inflows of 
technology to the affiliates of foreign MNCs. One problem, of course, is that some of these policies - especially those that promote competition - may be contrary to measures that are commonly used by host countries to attract new MNCs, e.g. import protection. In practice, it may therefore be necessary to weigh the benefits from larger inflows of technology to already present MNC affiliates against the possible costs in terms of foregone new investment from abroad. 


\section{Notes}

1. The surveys cover affiliates in about 50 individual countries, and the data are presented for aggregate manufacturing and seven broad industry groups. Gaps in the data have forced us to exclude many countries, and those remaining are Australia, Austria, Belgium, Canada, Chile, Colombia, Denmark, Ecuador, France, West Germany, Greece, Hong Kong, India, Indonesia, Ireland, Italy, Japan, Luxembourg, Malaysia, Netherlands, New Zealand, Norway, Panama, Peru, Philippines, Portugal, Singapore, South Korea, Spain, Sweden, Turkey, U.K., and Venezuela. Some estimations cover fewer countries because of missing observations.

2. It was not possible to calculate unweighted average license payments because of the many missing country/industry observations.

3. Technology transfers could also be proxied with data on the affiliates' $R \& D$ expenditures, since local $R \& D$ often require imports of technology from the parent company. However, the size and income level of the host economy are probably the only host characteristics that influence this proxy, as discussed by Zejan (1990), and we have therefore not included any R\&D variables.

4. Some other factors influencing technology transfers have been discussed in the literature. For instance, Katrak (1991) notes that affiliates are likely to use more capital-intensive technologies if there are minimum-wage laws that cause wage rates to exceed some market equilibrium rate, or if over-valued exchange rates subsidize the use of imported equipment and intermediaries. We have not included these factors in the analysis for lack of appropriate data.

5. The well-known Decision 24 of the Andean Investment Code, instituted in 1970/71, prohibited payments of royalties and license fees from wholly-owned affiliates to parents. If the rule had been implemented strictly, the variable LICENSE would, per definition, have been equal to zero for Bolivia, Colombia, Ecuador, Peru, and Venezuela. However, the number of exceptions has been large, and there did not seem to be any significant differences in the use of royalties and license fees between these countries and the rest of Latin America in the early 1980s. See Grosse (1989), pp. 113-131.

6. Our results may therefore reflect the international competition between MNCs from different countries. See e.g. Graham (1991) and Sölvell (1987).

7. ED2ND and ED3RD refer to 1980 , since data for 1982 were not available for all countries. 


\section{References}

Bardhan, P. (1990), "Symposium on the State and Economic Development." Journal of Economic Perspectives, Vol. 4, No. 3, 3-7.

Bhagwati, J. (1988), Protectionism. Cambridge, MA; MIT Press.

Blomström, M. (1989), Foreign Investment and Spillovers. London; Routledge.

Caves, R.E. (1982), Multinational Enterprise and Economic Analysis. Cambridge; Cambridge University Press.

Graham, E.M. (1991), "Strategic Management and Transnational Firm Behavior: A Formal Approach." in C.N. Pitelis and R. Sugden, The Nature of the Transnational Firm. London; Routledge.

Grosse, R. (1989), Multinationals in Latin America. London; Routledge.

Katrak, H. (1991), "Market Rivalry, Government Policies and Multinational Enterprise in Developing Countries." in P.J. Buckley and J. Clegg, eds., Multinational Enterprises in Less Developed Countries. London; Macmillan.

Kokko, A. (forthcoming), "Technology, Market Characteristics, and Spillovers." Journal of Development Economics.

Summers, R. and A. Heston (1988), "A New Set of International Comparisons of Real Product and Prices: Estimates for 130 Countries, 1950-1985." Review of Income and Wealth, Series 34, 1-26.

Sölvell, Ö. (1987), Entry Barriers and Foreign Penetration: Emerging Patterns of International Competition in Two Electrical Engineering Industries. Stockholm; Institute of International Business, Stockholm School of Economics.

UNESCO (1990), Statistical Yearbook 1990. Paris; UNESCO.

United Nations (various), Industrial Statistics Yearbook. New York; United Nations.

U.S. Department of Commerce (1985), U.S. Direct Investment Abroad: 1982 Benchmark Survey Data. Washington, D.C.; U.S. Government Printing Office.

Wang, Y. and M. Blomström (1992) "Foreign Investment and Technology Transfer: A Simple Model." European Economic Review, Vol. 36, 137-155.

Zejan, M. (1990), "R\&D Activities in Affiliates of Swedish Multinational Enterprises." Scandinavian Journal of Economics, Vol. 92, 487-500. 
Table 1 Measures of U.S. Majority-Owned Foreign Affiliates' (MOFAs) Payments of Royalties and License Fees and Imports of Capital Equipment, 1982 (weighted averages).

\begin{tabular}{|c|c|c|c|c|}
\hline & $\begin{array}{r}\text { LICENSE/ } \\
\text { SALES }\end{array}$ & $\begin{array}{r}\text { LICENSE/ } \\
\text { LABOR } \\
\text { (US\$) }\end{array}$ & $\begin{array}{r}\text { CAPIMP/ } \\
\text { SALES }\end{array}$ & $\begin{array}{r}\text { CAPIMP/ } \\
\text { LABOR } \\
\text { (US\$) }\end{array}$ \\
\hline Food products & 0.0049 & 450 & 0.0020 & 183 \\
\hline Chemical products & 0.0133 & 1,504 & 0.0018 & 197 \\
\hline Metal products & 0.0049 & 334 & 0.0057 & 388 \\
\hline Machinery & 0.0315 & 2,890 & 0.0106 & 969 \\
\hline Electric equipment & 0.0087 & 390 & 0.0055 & 246 \\
\hline Transport equipment & 0.0009 & 90 & 0.0058 & 574 \\
\hline Other manufacturing & 0.0118 & 761 & 0.0047 & 300 \\
\hline Total manufacturing & 0.0113 & 909 & 0.0050 & 405 \\
\hline $\begin{array}{l}\text { Total manufacturing, } \\
\text { developed countries }\end{array}$ & 0.0130 & 1,234 & 0.0040 & 378 \\
\hline $\begin{array}{l}\text { Total manufacturing, } \\
\text { developing countries }\end{array}$ & 0.0038 & 187 & 0.0095 & 464 \\
\hline
\end{tabular}


Table 2 Results of OLS Estimations. Payments of Royalties and License Fees by Affiliates 1982.

\begin{tabular}{|c|c|c|c|c|c|c|c|c|}
\hline Equation & Constant & $\begin{array}{l}\text { INV/ } \\
\text { EMPL }\end{array}$ & $\begin{array}{l}\text { INV/ } \\
\text { OUTPUT }\end{array}$ & PREQS & ED3RD & $\overline{\mathbf{R}}^{2}$ & $\mathbf{F}$ & $\mathbf{N}$ \\
\hline \multicolumn{9}{|c|}{ LICENSE/LABOR } \\
\hline (1) & $\begin{array}{c}0.0907 \\
(0.161)\end{array}$ & $\begin{array}{l}0.9446 \\
(3.099)^{* * * *}\end{array}$ & -- & $\begin{array}{l}-0.5075 \\
(2.575)^{* *}\end{array}$ & $\begin{array}{c}0.6536 \\
(1.695)\end{array}$ & 0.445 & 9.55 & 33 \\
\hline
\end{tabular}

LICENSE/SALES

$\begin{array}{ccccccccc}0.2016 & -- & 0.9250 & -0.5444 & 0.4178 & 0.348 & 6.51 & 32 \\ (0.402) & -- & (2.587)^{* *} & (3.140)^{+*+*} & (1.375) & & & \end{array}$

\section{LICDIF/LABOR}

(3)

$\begin{array}{cccccccc}0.2058 & 0.6335 & - & -0.3392 & 0.4999 & 0.477 & 10.71 & 33 \\ (0.559) & (3.178)^{* * *} & -- & (2.632)^{* *} & (1.982)^{*} & & & \end{array}$

LICDIF/SALES

(4)

$\begin{array}{cccccccc}0.7743 & - & 0.1610 & -0.1512 & 0.2158 & 0.382 & 7.40 & 32 \\ (5.080)^{*+*} & -- & (1.481) & (2.869)^{+*+} & (2.336)^{*+} & & & \end{array}$

LICDIF $* /$ LABOR

(5)

$\begin{array}{cccccccc}0.4102 & 0.4630 & -- & -0.0995 & 0.2263 & 0.252 & 4.59 & 33 \\ (1.372) & (2.858)^{++*} & - & (0.950) & (1.104) & & & \end{array}$

LICDIF*/SALES

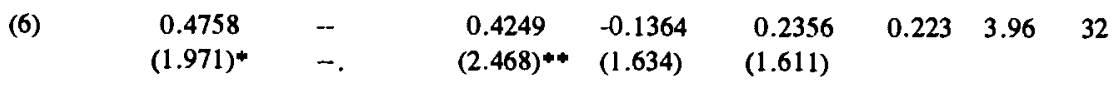

Notes: All variables appearing in the regression equations are scaled by division with the sample means. Estimated coefficients are shown together with the absolute value of the $t$-statistic in parentheses. *,**, and $* * *$ indicate significance at the 10,5 , and 1 per cent levels of confidence (two-tailed tests). For definitions of variables and data sources, see Appendix Table 1. 
Table 3 Results of OLS Estimations. Imports of Capital Equipment from the United States by Affiliates 1982.

INV/ INV/

\begin{tabular}{lllllllll} 
Equation Constant & EMPL & OUTPUT & PREQS & ED3RD & $\bar{R}^{2}$ & F & N \\
\hline
\end{tabular}

CAPIMP/LABOR

(7)

$\begin{array}{cccccccc}0.1514 & 0.6329 & - & 0.1867 & 0.0289 & 0.081 & 1.88 & 31 \\ (0.288) & (2.154)^{* *} & -- & (0.947) & (0.081) & & & \end{array}$

CAPIMP/SALES

$\begin{array}{lcccccccc}(8) & 0.3995 & - & 0.9594 & 0.0566 & -0.4154 & 0.084 & 1.88 & 30 \\ & (0.558) & -- & (1.840)^{*} & (0.214) & (0.979) & & & \end{array}$

\section{CAPDIF/LABOR}

(9)

$\begin{array}{cccccccc}0.2277 & 0.5391 & -- & 0.2623 & -0.0291 & 0.082 & 1.90 & 31 \\ (0.453) & (1.919)^{*} & -- & (1.391) & (0.086) & & & \end{array}$

\section{CAPDIF*/LABOR}

(10)

$\begin{array}{cccccccc}0.2393 & 0.5107 & - & 0.1407 & 0.1093 & 0.034 & 1.35 & 31 \\ (0.469) & (1.792)^{*} & - & (0.736) & (0.317) & & & \end{array}$

Note: All variables appearing in the regression equations are scaled by division with the sample means. Estimated coefficients are shown together with the absolute value of the t-statistic in parentheses. * $* *$, and $* * *$ indicate significance at the 10,5 , and 1 per cent levels of confidence (two-tailed tests). For definitions of variables and data sources, see Appendix Table 1. 
Appendix Table 1 List of Variables and Data Sources

DEPENDENT VARIABLES: proxies for the technology imports of U.S. MOFAs (Basic data are from U.S. Department of Commerce, 1985.)

LICENSE

LICDIF

LICDIF*

CAPIMP

CAPDIF

CAPDIF*

(continued...)
- payments of royalties and license fees to the U.S. by U.S. MOFAs in host country i 1982.

- difference between LICENSE and expected license payments, defined for each country $i$ as

$\operatorname{LICENSE}_{\mathrm{i}}-\boldsymbol{\Sigma}_{\mathrm{j}}\left(\mathrm{LABOR}_{\mathrm{ij}} *\right.$ AVELIC $\left._{\mathrm{j}}\right)$

where $\mathrm{LABOR}_{i j}$ is the employment in country i's industry $\mathrm{j}$ and $\mathrm{AVELIC}_{\mathrm{j}}$ is the unweighted average license payment per employee in industry $\mathrm{j}, \boldsymbol{\Sigma}_{\mathrm{i}} \operatorname{LICENSE}_{\mathrm{ij}} / \boldsymbol{\Sigma}_{\mathrm{i}}$ $\operatorname{EMPL}_{\mathrm{ij}}$.

- as LICDIF, but AVELIC calculated separately for developed and developing countries.

- imports of capital equipment from the U.S. by U.S. MOFAs in host country i 1982.

- difference between CAPIMP and expected imports of capital equipment, calculated as LICDIF.

- as CAPDIF, but average capital imports calculated separately for developed and developing countries. 
Appendix Table 1 (continued...)

INDEPENDENT VARIABLES (Data sources in parentheses.)

INV/EMPL

- gross fixed investment per employee in each host country's manufacturing sector 1982 (excluding U.S. MOFAs), corrected for international price differences for capital goods. Proxy for local competition. (Industrial Statistics Yearbook, various; Summers and Heston, 1988.)

INV/OUTPUT - ratio of gross fixed investment to gross output in each host country's manufacturing sector 1982 (excluding U.S. MOFAs). Proxy for local competition. (Industrial Statistics Yearbook, various.)

TREQS

- share of U.S. affiliates in each host country facing various technology transfer requirements 1982. (U.S. Department of Commerce, 1985.)

PREQS

- share of U.S. affiliates in each host country facing various performance requirements 1982. (U.S. Department of Commerce, 1985.)

ED2ND

- per cent of age group (13-18) in secondary level education 1980 in each host country. Proxy for labor skills. (UNESCO Statistical Yearbook, 1990.)

ED3RD

- per cent of age group (18-24) in third level education 1980 in each host country. Proxy for labor skills. (UNESCO Statistical Yearbook, 1990.) 
Appendix Table 2 Simple Correlation Coefficients

for Independent Variables.

INV/EMPL $\quad 1.00$

INV/OUTPUT $\quad 0.52 \quad 1.00$

$\begin{array}{llll}\text { ED2ND } & 0.12 & -0.33 & 1.00\end{array}$

$\begin{array}{lllll}\text { ED3RD } & 0.20 & -0.08 & 0.67 & 1.00\end{array}$

$\begin{array}{llllll}\text { PREQS } & -0.04 & 0.36 & -0.75 & -0.39 & 1.00\end{array}$

$\begin{array}{lllllll}\text { TREQS } & -0.06 & 0.55 & -0.64 & -0.49 & 0.52 & 1.00\end{array}$

$\begin{array}{llllll}\text { INV/ INV/ } & \text { ED2ND } & \text { ED3RD } & \text { PREQS } & \text { TREQS } \\ \text { EMPL } & \text { OUTPUT } & & & \end{array}$

Note: There are 33 observations for all variables except INV/OUTPUT $(\mathrm{N}=32)$. For data sources and definitions of variables, see Appendix Table 1. 